\title{
KERATOPLASTY CLAMP*
}

\author{
BY \\ P. SIVASUBRAMANIAM \\ Jaffna, Ceylon
}

OPHTHALMIC surgeons and instrument manufacturers have been jointly responsible for turning out a number of useful keratoplasty instruments; some of these are difficult to obtain either because their cost is prohibitive or because exchange regulations do not permit their importation. The appliance described below is not a new " gadget " but a very old instrument put to a new use. In fixing a corneal graft to the host by direct sutures the graft has to be held in a manner least damaging to the graft while the sutures are being placed. Arruga's box forceps in various sizes are used by many surgeons, but to many of us scattered over the globe this additional armamentarium amounts to a luxury and also, in lamellar keratoplasty, shapes other than circular may have to be employed in which case Arruga's box forceps are unsuitable.

I have used the following appliance and find it satisfactory. Two lengths of rubber tubing about $1 \frac{1}{2}$ " long are slipped over the blades of a fixation forceps (Elschnig's preferably) leaving the teeth bare (Fig. 1).

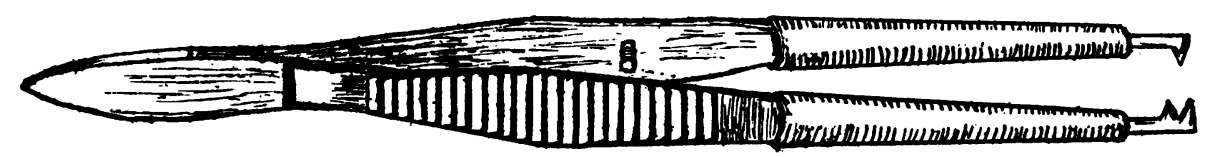

FIG. 1.-Elschnig's fixation forceps with rubber sleeves on the two blades.

This imitation of gastric and intestinal clamps constitutes the whole gadget. In transferring the graft on to the "clamp" care is taken to see that the epithelial side is towards the male blade of the forceps, that on which the manufacturer's name is inscribed. This practice will guard against the wrong aspect of the graft being apposed to the host. Small grafts could be clamped by the distal portions of the tapering rubbersleeved blades, and larger grafts may be held by the proximal portions. Fig. 2 shows how the graft is held and the sutures passed. The thumb and index finger are used to keep the blades apposed.

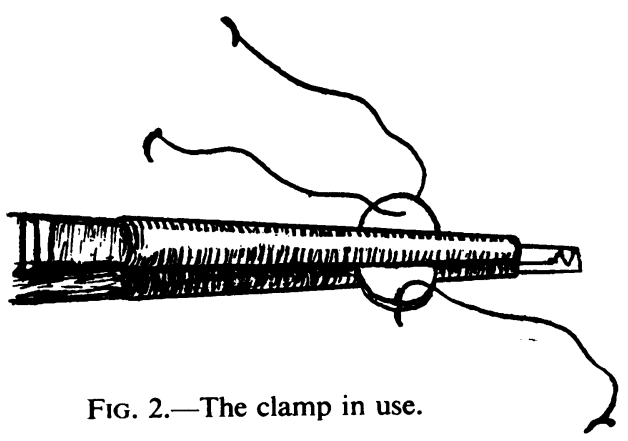
Any number of sutures can be placed successively by rotating the graft.

*Received for publication September 10, 1953. 